\title{
On the tension-tension fatigue behaviour of a carbon reinforced thermoplastic part II: evaluation of a dumbbell-shaped specimen
}

\author{
I. De Baere ${ }^{1}$, W. Van Paepegem ${ }^{1}$, C. Hochard ${ }^{2}$ and J. Degrieck ${ }^{1}$ \\ ${ }^{1}$ Department of Materials Science and Engineering, Faculty of Engineering, Ghent University. \\ Sint-Pietersnieuwstraat 41, B-9000 Gent, Belgium. \\ ${ }^{2}$ Laboratoire de Mécanique et d’Acoustique, CNRS, Université aix Marseille \\ 31 Chemin Joseph Aiguier, F-13402 Marseille 20, France.
}

E-mail: Ives.DeBaere@UGent.be

\begin{abstract}
For performing uni-axial fatigue tests on composite materials, the ASTM D3479/D3479M Standard Test Method for Tension-Tension Fatigue of Polymer Matrix Composite Materials is often considered. This standard prescribes a rectangular shaped specimen with end tabs. However, in part I of this study it became clear that for some materials, such as the carbon PPS under study, the proposed geometry is not ideal for fatigue tests. In this manuscript, a dogbone shape is assessed to see whether it performs better under fatigue loading conditions, primarily meaning that failure does not occur in the tabbed section. The shape is first optimised using finite element modelling, after which fatigue experiments are performed. It may be concluded that for the material under study, the dogbone shape is preferable over the rectangular, since failure never occurred under or near the tabbed section and that fatigue life is highly underestimated when using the rectangular specimen.
\end{abstract}

Keywords: Fatigue, dogbone, carbon fibre, thermoplastic

\section{Introduction}

When performing quasi-static tests on fibre-reinforced materials, the use of end tabs is often necessary to prevent failure in the grips. Both the ASTM D3039/D3039M Standard Test Method for Tensile Properties of Polymer Matrix Composite Materials and the ISO 527-1 International standard for the determination of tensile properties suggest using end tabs on the specimen and offer guidelines on the dimensions of the end tabs.

When performing uni-axial fatigue tests, clamp failure is even more likely to occur. The ASTM D3479/D3479M Standard Test Method for Tension-Tension Fatigue of Polymer Matrix Composite Materials states that end tabs should always be used, using the same geometry recommendations as in the ASTM D3039/D3039M Standard.

It is well known that underneath the end-tabs, stress concentrations exist due to the clamping of the specimen $[2,3,4,5]$; the absolute value of the stress concentration factor depends on various parameters, such as the used geometry, adhesive, gripping principle, material combination and stacking sequence of the composite. For most materials, this stress concentration does not pose a problem, since after a certain load level the specimen starts to narrow at a certain location, where failure is then most likely to occur. However, some materials, such as the carbon-fabric reinforced polyphenylene 
sulphide under study, do not have the tendency to narrow because of the very low Poisson's ratio and as such, failure is most likely to occur in the area of the stress concentration, underneath the end tabs. In the first part of this study [1], several combinations of adhesives, tab materials and tab geometries were examined under static loading conditions, but no acceptable failure was achieved. Furthermore, during tension-tension fatigue loading conditions, failure always occurred in the tabbed section.

This article assesses the use of a dogbone-shaped specimen for both uni-axial quasistatic and fatigue tests. Although dogbone shapes are mostly used for pure polymers and sheet metals and are not accepted for continuous fibre reinforced composites (ISO 5274), the authors feel that failure occurring in the centre of a slightly curved specimen, with a well known stress state, is preferable over having repeated failure in the gripped section underneath the end-tabs. Also, the material under study is a fabric, so the typical shear out failure, which might occur with unidirectionally reinforced dogbone specimens, is not likely to happen. Finally, according to all three mentioned standards, the results of an experiment with a failure in the gripped section should not be taken into account, as it is always an underestimation of the failure.

It must be noted that end tabs will still be considered in this study. Despite the disadvantage of the stress concentration, they still protect the specimen from the serrated surface of the grips and allow a smooth introduction of the gripping pressure.

With regard to the use of dogbone specimens in literature, not many articles were found. A search on the Web of Science, including the ISI proceedings using the key word 'dogbone' only yielded 136 articles, of which only a few are related to the use of dogbone specimens for fibre reinforced composite testing. Searching for the key words 'waisted AND composite' resulted in 9 articles. Dogbone specimens are used for single [6] or double $[7,8]$ fibre fragmentation tests to determine the interfacial shear strength. Furthermore, dogbones can be considered for compressive testing [9, 10, 11]. In [12] a dogbone shape is used to obtain acceptable failure, but only static tests were considered. Also, the geometry is different from the one presented here. Aceves et al. [13] considered a dogbone shape to illustrate their design methodology, but did not mention fatigue experiments. Finally, a study for NASA [14] reported the use of a similar dogbone geometry for fatigue, similar to the one considered in this manuscript.

In some cases, a dogbone like shape is used for testing, but it is not mentioned. This was the case in [15], where a dogbone shape is used for fatigue testing of glass fibre reinforced polypropylene. A dogbone shape, similar to the one considered in this manuscript, was also considered for bending fatigue in [16] and uni-axial faituge of a carbon-epoxy in [17], but they also did not draw any attention to it. The authors assume that there are other studies using dogbones, but where this specific geometry is not mentioned, making these studies hard to find.

The next paragraph describes the used material and gives more detail on the used specimen geometry, in combination with a finite element assessment of the dogbone geometry. Then, the experiments, both under quasi-static and fatigue loading conditions are discussed and finally, some conclusions are drawn. 


\section{Materials and Equipment}

\subsection{Composite Material}

The material under study was a carbon fibre-reinforced polyphenylene sulphide (PPS), called CETEX. This material is supplied to us by Ten Cate. The fibre type is the carbon fibre T300J 3K and the weaving pattern is a 5-harness satin weave with a mass per surface unit of $286 \mathrm{~g} / \mathrm{m}^{2}$. The 5-harness satin weave is a fabric with high strength in both directions and excellent bending properties.

The carbon PPS plates were hot pressed, only one stacking sequence was used for this study, namely a $\left[\left(0^{\circ}, 90^{\circ}\right)\right]_{4 \mathrm{~s}}$ where $\left(0^{\circ}, 90^{\circ}\right)$ represents one layer of fabric.

The in-plane elastic properties of the individual carbon PPS lamina were determined by the dynamic modulus identification method as described in [18] and are listed in Table 1.

Table 1 In-plane elastic properties of the individual carbon/PPS lamina (dynamic modulus identification method).

\begin{tabular}{lcr}
\hline $\mathrm{E}_{11}$ & 56.0 & $\mathrm{GPa}$ \\
$\mathrm{E}_{22}$ & 57.0 & $\mathrm{GPa}$ \\
$\nu_{12}$ & 0.033 & - \\
$\mathrm{G}_{12}$ & 4.175 & $\mathrm{GPa}$ \\
\hline
\end{tabular}

The tensile strength properties were determined at the Technical University of Delft and are listed in Table 2.

Table 2 Tensile strength properties of the individual carbon/PPS lamina (Mechanical testing at TUDelft).

\begin{tabular}{lcc}
\hline $\mathrm{X}_{\mathrm{T}}$ & 734.0 & $\mathrm{MPa}$ \\
$\varepsilon_{11}$ ult & 0.011 & - \\
$\mathrm{Y}_{\mathrm{T}}$ & 754.0 & $\mathrm{MPa}$ \\
$\varepsilon_{22}$ ult & 0.013 & - \\
$\mathrm{S}_{\mathrm{T}}$ & 110.0 & $\mathrm{MPa}$ \\
\hline
\end{tabular}

\subsection{Equipment}

All tensile tests were performed on a servo-hydraulic INSTRON 8801 tensile testing machine with a FastTrack 8800 digital controller and a load cell of $\pm 100 \mathrm{kN}$. The quasistatic tests were displacement-controlled with a speed of $2 \mathrm{~mm} / \mathrm{min}$.

A special fixture is mounted on the tensile machine to prevent relative rotation of the grips, causing torsion of the specimen and alignment of the grips was established using an INSTRON alignment kit.

For the registration of the tensile data, a combination of a National Instruments USB 6251 data acquisition card and the SCB-68 pin shielded connecter were used. The load, displacement and strain, given by the FastTrack controller were sampled on the same time basis.

\section{Specimen geometry}

\subsection{Theoretical deduction}

As mentioned in the introduction, stress concentrations are present underneath the end tabs. In a previous study, the authors have assessed different geometries and gripping 
strategies for the material under study [2] and determined the stress concentration factors underneath the end tabs. This article concluded that straight edged tabs with $\left[\left(0^{\circ}, 90^{\circ}\right)\right]_{4 \mathrm{~s}}$ stacking sequence, mounted completely inside the grips, gave best results, when both experiments and finite element simulations are taken into account. This strategy yields a stress concentration factor as result of the tabs $\left(\mathrm{s}_{t}\right)$ of 1.3 , with the stress concentration underneath the edge of the end tab. The idea here is to have a slight curvature of the specimen, so that this stress concentration is compensated by having a less wide specimen. This is shown in Figure 1. It should be noted that the geometry differs from the ones mostly found in literature: in most cases, there is a constant section in between the two curved areas [12, 15], whereas here, the curved section has a constant radius and thus a constantly varying width. The reason for the constant radius will become clear in the finite element assessment.

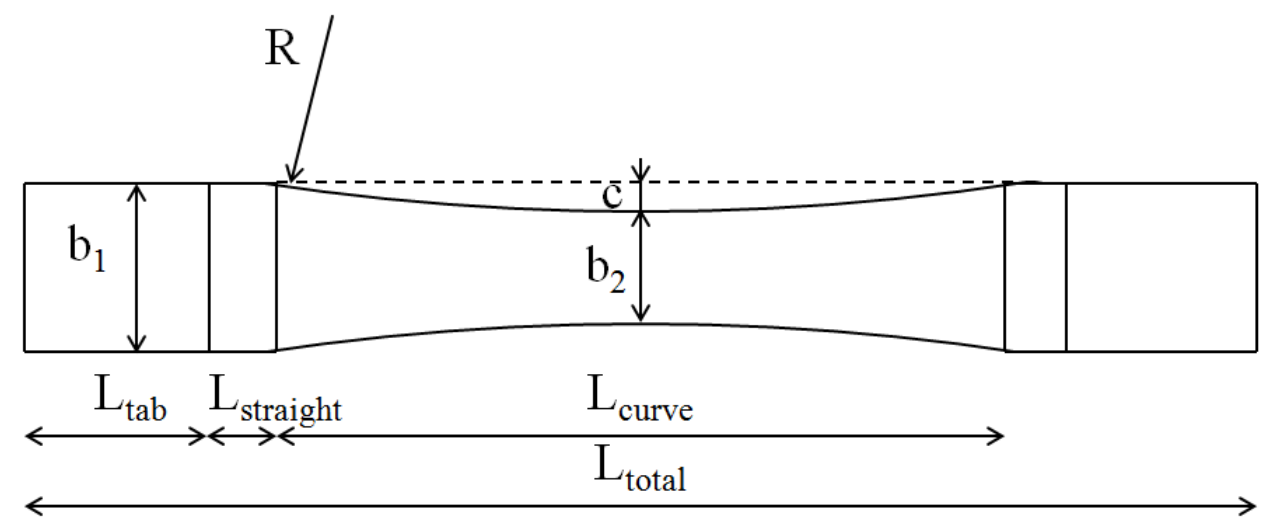

Figure 1 Illustration of the proposed dogbone shape.

In this figure, $L_{\text {total }}$ represents the entire length of the specimen. Only the length $L_{\text {curve }}$ is curved with a constant radius $\mathrm{R}$. In order to bond tabs, a length of $\mathrm{l}_{\text {tab }}$ is provided and, according to St-Venants principle, a short length of $\mathrm{L}_{\text {straight }}$ should be sufficient so that the stress concentration of the tabs do not interfere with the start of the curvature. $b_{1}$ is the original width of the specimen and $b_{2}$ is the smallest width, in the middle of the specimen. The thickness of the specimen is $2.5 \mathrm{~mm}$, corresponding with the eight layers in the composite layup $\left[\left(0^{\circ}, 90^{\circ}\right)\right]_{4 s}$.

If a force $\mathrm{F}[\mathrm{N}]$ is applied, then the maximum stress $\sigma_{\mathrm{xx}}[\mathrm{MPa}]$ in a straight specimen with end tabs will be:

$$
\sigma_{x x}=s_{t} \frac{F}{b_{1} t}
$$

$\mathrm{t}[\mathrm{mm}]$ being the thickness of the specimen and $\mathrm{s}_{\mathrm{t}}[-]$ the stress concentration factor, resulting from the tabs. If the stress in the middle of the specimen must be equal or larger, then the following equation must apply:

$$
b_{2} \leq \frac{b_{1}}{s_{t}}
$$

The width $b_{2}[\mathrm{~mm}]$ can be derived using simple goniometry.

$$
b_{2}=b_{1}-2 c
$$

The parameter c [mm] can be calculated, using Pythagoras, yielding

$$
c=R-\sqrt{R^{2}-\left(\frac{l_{\text {curve }}}{2}\right)^{2}}
$$


In the previous deduction, it is assumed that there is no stress concentration due to the curvature of the dogbone, only the stress concentration underneath the end tabs is taken into account. However, it is expected that a small stress concentration as result of the radius might be present, meaning that the stresses in the centre of the specimen will be even higher than in Equation 1. As such, there is an extra safety factor of failure occurring in the curved zone, rather than underneath the tabs. Therefore, we use the equality in Equation 2. Combining this with Equations 3 and 4 and solving for $\mathrm{R}$ [mm] yields:

$$
R=\frac{\left(\frac{s_{t}-1}{s_{t}}\right)^{2} b_{1}^{2}+l_{\text {curve }}^{2}}{4\left(\frac{s_{t}-1}{s_{t}}\right) b_{1}}
$$

As a result, using a given $\mathrm{L}_{\text {curve }}$ and a given width $\mathrm{b}_{1}$, Equation 5 yields a lower boundary for the necessary radius to obtain the stress in the middle of the specimen being equal or higher than the stress concentration underneath the tabs, with given stress concentration factor $\mathrm{s}_{\mathrm{t}}$.

In order to determine an interesting set of dimensions, there are two possible procedures: (i) experimentally test different geometries and verify which geometry gives the best results or (ii) model the geometry in finite element software and asses the geometry numerically. The authors have chosen the second option, which is described next.

\subsection{Finite element assessment}

\subsubsection{Introduction}

The stress concentrations resulting from the use of end tabs has already been extensively documented by the authors in [2]. Here, it can be seen that the stress concentration lies at the end of the tabs and after about $5 \mathrm{~mm}$, the stress level has reached its nominal value. So if the length $L_{\text {straight }}$ is taken sufficiently large (i.e. $5 \mathrm{~mm}$ or longer) then the stress concentration will not influence the stress distribution in the curved section. As such, the pressure of the grips and the geometry of the end tabs are not taken into account in the simulations in this manuscript, although the area underneath the end tabs will still be modelled.

For this numerical assessment, already most of the parameters of the geometry have certain boundaries. To assure that transverse strain gauges can still be mounted in the centre of the specimen, the width $b_{2}$ and therefore the width $b_{1}$ (Equation 2) cannot be too small. For the given stress concentration factor of 1.3 which is considered here, a width $b_{1}$ equal to $30 \mathrm{~mm}$ yields a $b_{2}$ equal to $23.1 \mathrm{~mm}$, which the authors consider the lowest acceptable value. For narrower specimens, the transverse strain gauge would suffer from edge effects and are, therefore, not considered. High values for $b_{1}$ are also not preferred, as a wider specimen requires higher failure forces and therefore larger end tabs to transfer the load. Furthermore, the width is limited by the maximum width the hydraulic grips are able to clamp.

The length $\mathrm{L}_{\text {curve }}$ is expected to have the largest influence on the stress distribution, but again, certain limits apply. The longer $\mathrm{L}_{\text {curve }}$ the longer the entire specimen becomes. Moreover, the longer the specimen, the more displacement needs to be imposed on the specimen for a given strain. As such this value will also be limited by the capacity of the 
hydraulic tensile machine under fatigue loading conditions. The geometries, given in Table 3 are therefore considered here, in order to determine the influence of these parameters and to assess the occurring stress distribution.

Table 3 Overview of the simulated geometries.

\begin{tabular}{cccccc}
\hline $\begin{array}{c}\mathrm{L}_{\text {total }} \\
{[\mathrm{mm}]}\end{array}$ & $\begin{array}{c}\mathrm{L}_{\text {tab }}+\mathrm{L}_{\text {straight }} \\
{[\mathrm{mm}]}\end{array}$ & $\begin{array}{c}\mathrm{L}_{\text {curve }} \\
{[\mathrm{mm}]}\end{array}$ & $\begin{array}{c}\mathrm{b}_{1} \\
{[\mathrm{~mm}]}\end{array}$ & $\begin{array}{c}\mathrm{R}(\mathrm{Eq} .5) \\
{[\mathrm{mm}]}\end{array}$ & $\begin{array}{c}\mathrm{b}_{2} \\
{[\mathrm{~mm}]}\end{array}$ \\
200 & $45+5$ & 100 & 30 & 362.8 & 23.1 \\
300 & $45+5$ & 200 & 30 & 1446 & 23.1 \\
300 & $45+5$ & 200 & 40 & 1086 & 30.8 \\
400 & $45+5$ & 300 & 30 & 3252 & 23.1 \\
\hline
\end{tabular}

\subsubsection{Finite element model}

In order to save calculation time, only one quarter of the specimen is modelled; the end of the specimen, where the end-tabs are mounted, is also modelled, but as previously mentioned, the end tabs and grip pressure is not taken into account. Figure 2 illustrates the used model for the simulation with $\mathrm{R}$ equal to $362.8 \mathrm{~mm}$, the used finite element software was ABAQUSTM/standard.

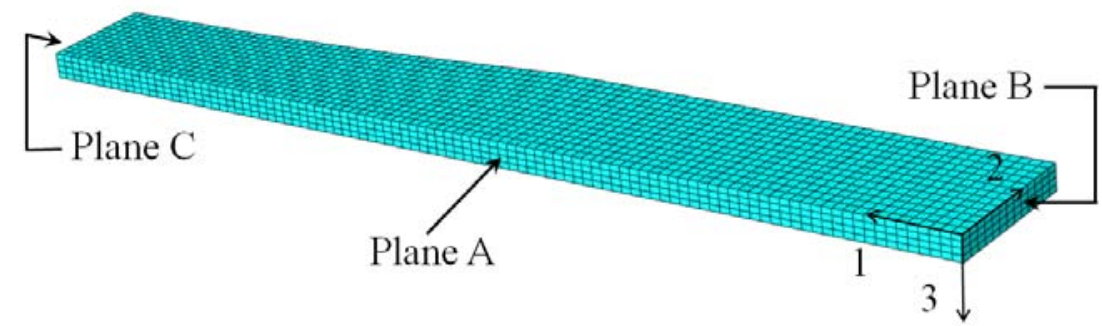

Figure 2 Illustration of the used mesh and boundary conditions.

The specimen was meshed with quadratic brick elements with reduced integration, called C3D20R with a mesh size of $1 \mathrm{~mm}$. The following boundary conditions were imposed: on plane $\mathrm{A}, \mathrm{u}_{2}=0$; on plane $\mathrm{B}, \mathrm{u}_{1}=0$ and to prevent a rigid body motion in the 3 -direction, the entire middle plane of the specimen is given $u_{3}=0$. Since 3D elements are used, there are no rotational degrees of freedom. On plane $\mathrm{C}$, a tensile stress of $100 \mathrm{MPa}$ is imposed. The absolute value of this stress is not important, as the simulation is linear elastic, but by choosing a multiple of 10 , it is easy to see the stress concentrations which may exist in the curved section on the contourplots. For the simulations here, the stress concentration factor $\mathrm{s}_{\text {curve }}$ is given by the following equation:

$$
S_{\text {curve }}=\frac{\sigma_{x x}^{\max }}{100}
$$

As previously mentioned, the end tabs as well as the grip pressure are not considered here. Following Saint-Venant's principle, the length $\mathrm{L}_{\text {straight }}$ should be long enough in all cases so that there is no interference with the stress distribution in the centre of the dogbone specimen, or even at the starting point of the curvature.

For the material, the following material properties are implemented (Table 4) [19]:

Table 4 Engineering constants implemented in ABAQUS ${ }^{\mathrm{TM}}$. 


\begin{tabular}{ccccccccc}
\hline $\mathrm{E}_{11}[\mathrm{MPa}]$ & $\mathrm{E}_{22}[\mathrm{MPa}]$ & $\mathrm{E}_{33}[\mathrm{MPa}]$ & $v_{12}[-]$ & $v_{13}[-]$ & $v_{23}[-]$ & $\mathrm{G}_{12}[\mathrm{MPa}]$ & $\mathrm{G}_{13}[\mathrm{MPa}]$ & $\mathrm{G}_{23}[\mathrm{MPa}]$ \\
56000 & 57000 & 9700 & 0.033 & 0.38 & 0.38 & 4175 & 2904 & 2902 \\
\hline
\end{tabular}

\subsubsection{Finite element results}

Figure 3 shows the longitudinal stress $\sigma_{\mathrm{xx}}$ for the specimen with $\mathrm{L}_{\text {curve }}=100$ with a corresponding radius of $362.8 \mathrm{~mm}$. As was expected, the stresses increase towards the centre of the specimen, but a fairly large stress concentration is present near the centre of the specimen. This is depicted in Figure 3 (b) in more detail with an adjusted scale.
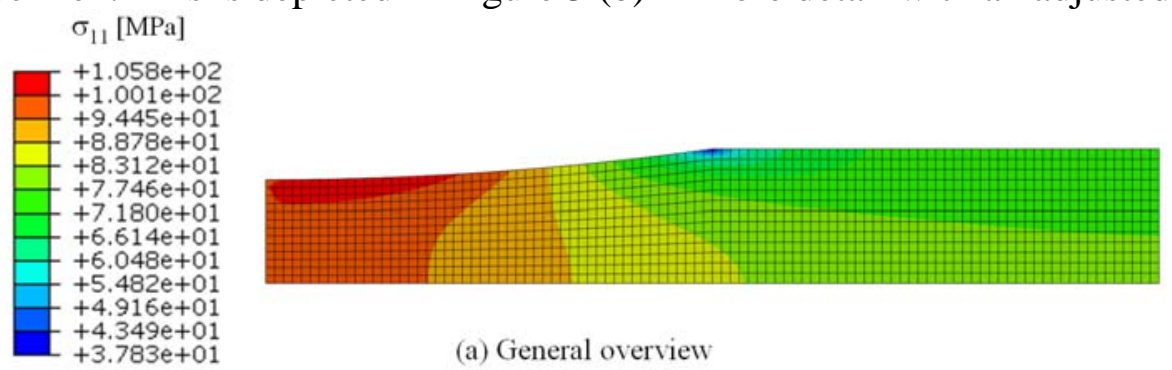

(a) General overview

$$
\sigma_{11}[\mathrm{MPa}]
$$
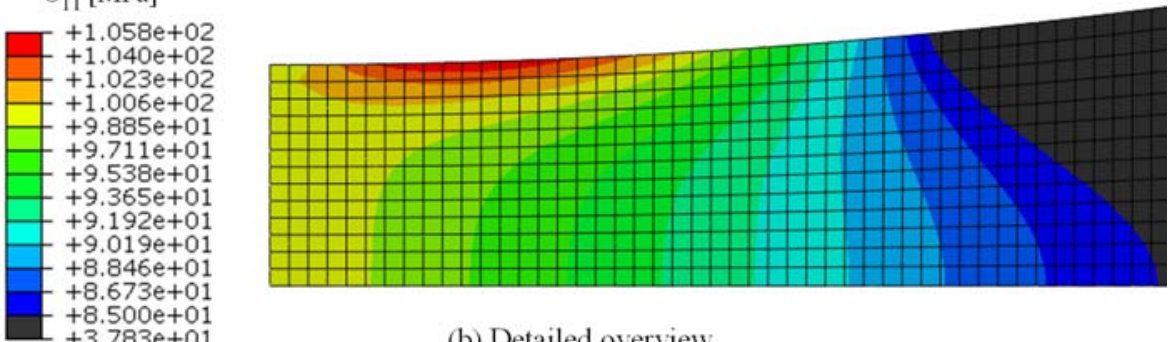

(b) Detailed overview

Figure 3 Longitudinal stress for the dogbone with R equal to $362.8 \mathrm{~mm}$, general overview.

From the results in Figure 3, the stress concentration factor $\mathrm{s}_{\text {curve }}$ can be calculated and yields a value of 1.058. This also explains why in [15] for their $0^{\circ}$ lay-up, the failure occurred just after the circular section in the smallest cross-section of their dumbbell specimen.

It is expected that for longer curved sections, the stress distribution will be more smoothly. As such, the geometry with a length of $400 \mathrm{~mm}$ is considered next. The longitudinal stress distribution is depicted in Figure 4. As can be noted, the distribution is indeed smoother than the previous simulation and the stress concentration is negligible. For this case, a stress concentration factor $\mathrm{s}_{\text {curve }}$ of 1.009 is found. 


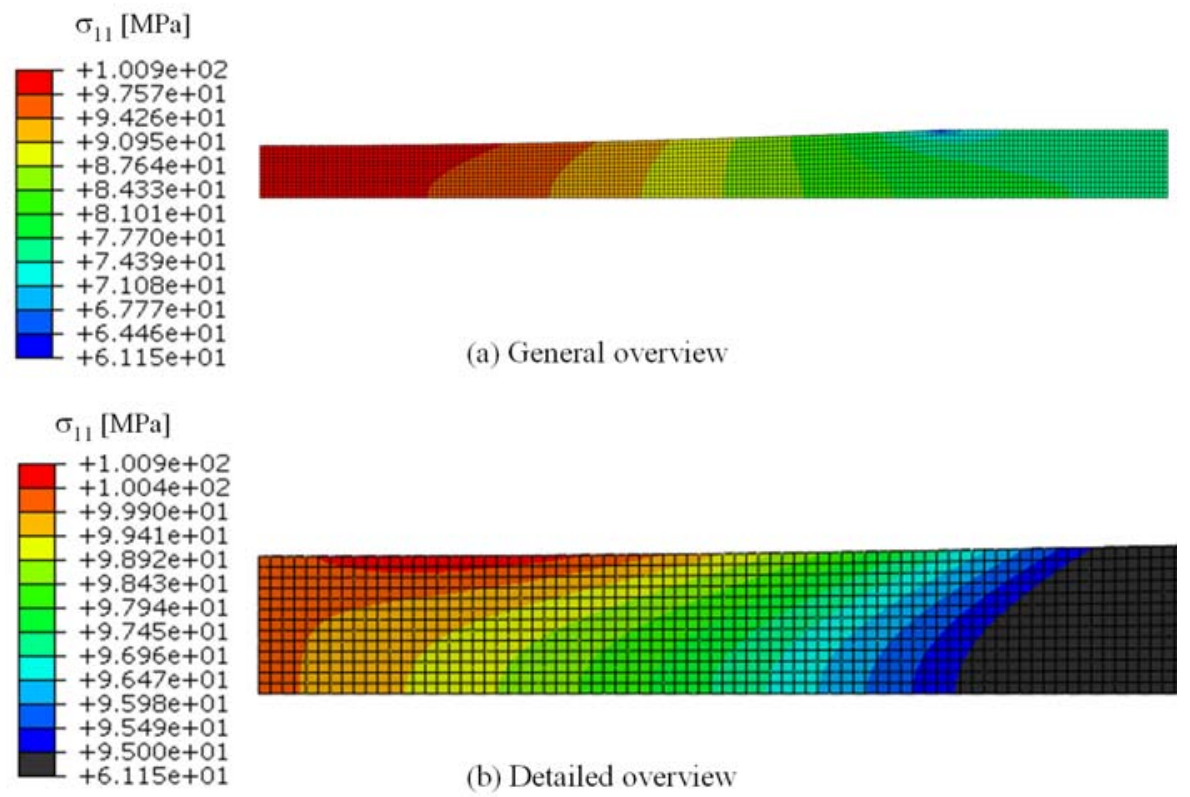

Figure 4 Longitudinal stress for the $400 \mathrm{~mm}$ long geometry.

However, a specimen of $400 \mathrm{~mm}$ is already quite long and will yield rather large displacements during fatigue tests with maximum strains around $1 \%$. Therefore, a total length of $300 \mathrm{~mm}$ is considered next. In order to evaluate the effect of the width of the specimen, both $30 \mathrm{~mm}$ and $40 \mathrm{~mm}$ are considered. These results are illustrated in Figure 5 , only the detailed overviews are given. It can be noted that increasing the width for a given curved length increases the value and size of the stress concentration. For these geometries, stress concentration factors of 1.019 and 1.026 are found for $30 \mathrm{~mm}$ and $40 \mathrm{~mm}$ width respectively.

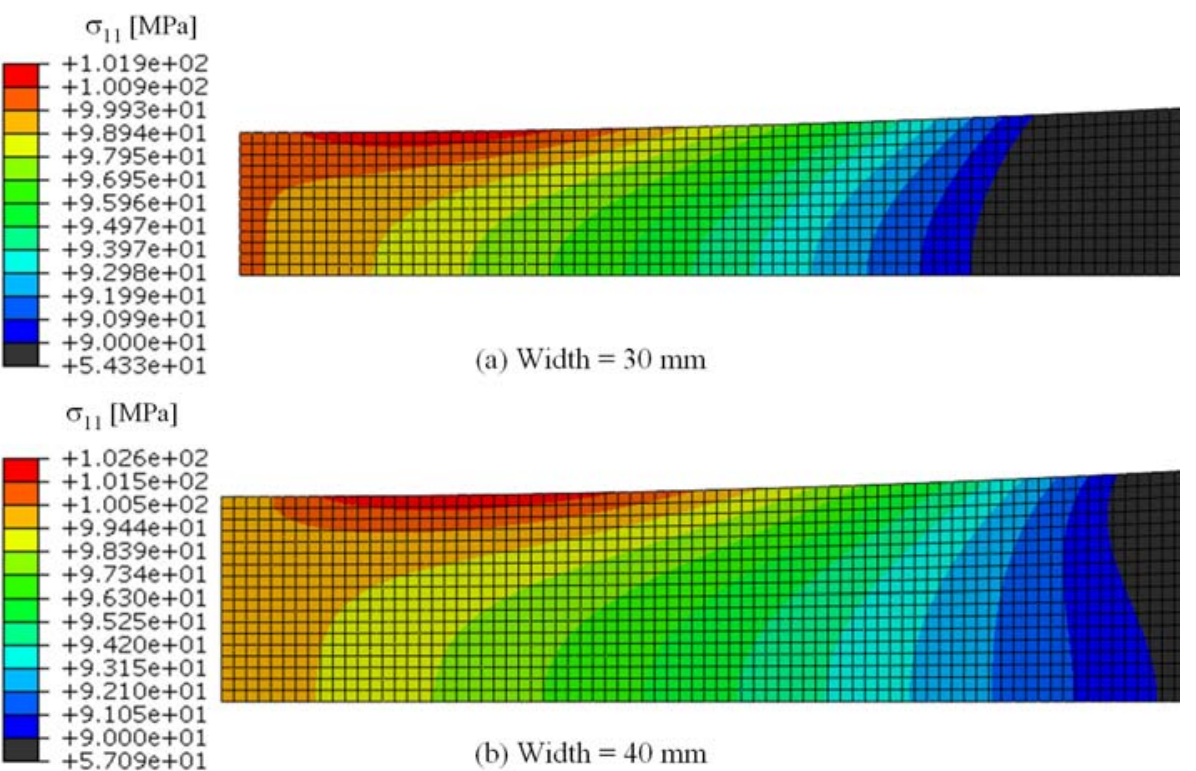

Figure 5 Comparison of the longitudinal stress distributions for the width equal to $30 \mathrm{~mm}$ and $40 \mathrm{~mm}$.

Finally, one could state that because the width is not constant in the centre of the specimen, there will be a variation in the longitudinal strain in that area. Since the strain will be measured with an extensometer during the fatigue experiments, this could influence the measurement because this device measures the strain over a certain length and therefore averages out the variations. However, as can be seen in the longitudinal strain distribution, depicted in Figure 6 for $\mathrm{R}=1446 \mathrm{~mm}$ and a width of $30 \mathrm{~mm}$, this 
variation is minimal. Over $8.12 \mathrm{~mm}$ away from the centre of the specimen, so over $16.24 \mathrm{~mm}$ in the centre in total, the strain has a uniform distribution between 0.001734 and 0.001757 , corresponding to the imposed $100 \mathrm{MPa}$.

Since the extensometer will be mounted in the centre of the specimen and failure is therefore very likely to occur between the two blades of the extensometer, a gauge length of $10 \mathrm{~mm}$ will be used. This length is smaller than the $16.24 \mathrm{~mm}$ of uniform strain field, so a correct strain measurement is expected.

With the $10 \mathrm{~mm}$ gauge length, the extensometer can see up to $10 \%$ of strain, so should failure indeed occur between the blades, then the limits of the hydraulic tensile machine should trip before failure of the extensometer.

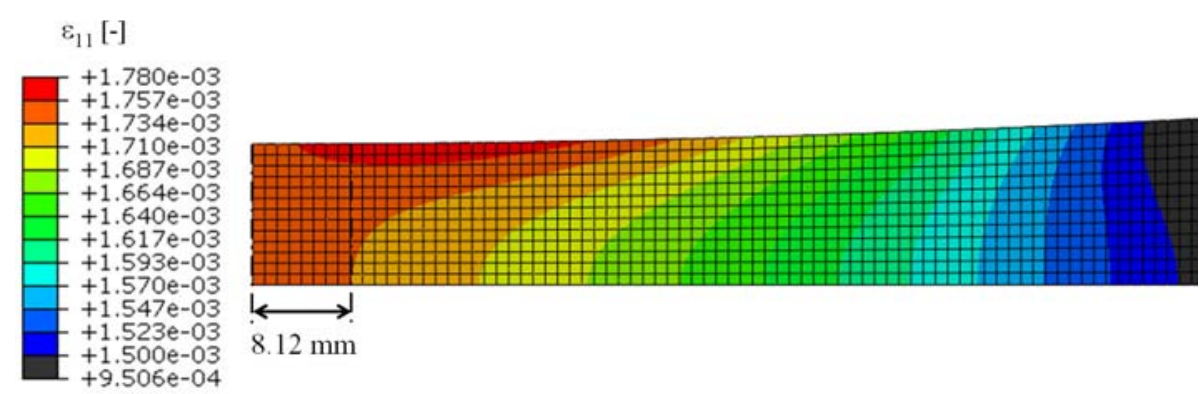

Figure 6 Longitudinal strain distribution for the geometry with R equal to $1446 \mathrm{~mm}$ (detailed view).

Considering the results from the finite element simulations, the geometry with $\mathrm{L}_{\text {total }}=300 \mathrm{~mm}$ and $\mathrm{R}=1446 \mathrm{~mm}$ will be used for the experimental validation. The dogbone specimens are cut out of a big laminate using a water jet, which uses a $\mathrm{CAD} / \mathrm{CAM}$ system, so the imposed geometry is followed accurately. Moreover, extra precautions were taken so no delaminations originated during the water jet cutting.

\section{Experiments and Discussion}

Now that the dimensions of the specimen are fixed, the geometry can be validated experimentally. In the next paragraph, quasi-static tests are discussed and then, fatigue experiments are conducted.

\subsection{Quasi-static testing}

Previous experiments with rectangular specimens, done by the authors yielded average failure stresses between 600 and $700 \mathrm{MPa}$, with occasionally a value higher than 700 [1, 18]. However, in almost all cases, failure occurred in the tabbed section. Similar to these experiments, all quasi-static experiments described here were done displacementcontrolled with a displacement speed of $2 \mathrm{~mm} / \mathrm{min}$.

Figure 7 shows the $\sigma_{\mathrm{xx}}$ as function of $\varepsilon_{\mathrm{xx}}$ for two experiments with $\mathrm{R}=1446 \mathrm{~mm}$. The second curve is given an offset along the $\mathrm{x}$-axis for a better view. It should be noted that the derived stiffness corresponds well with the values determined with the resonalyser method (Table 1), meaning that the slightly non-uniform strain field does not corrupt the extensometer measurement. Around $700 \mathrm{MPa}$, the extensometer was removed to avoid damage of this device when the specimen fails. The experiments, however, were then continued to determine the failure stress. 


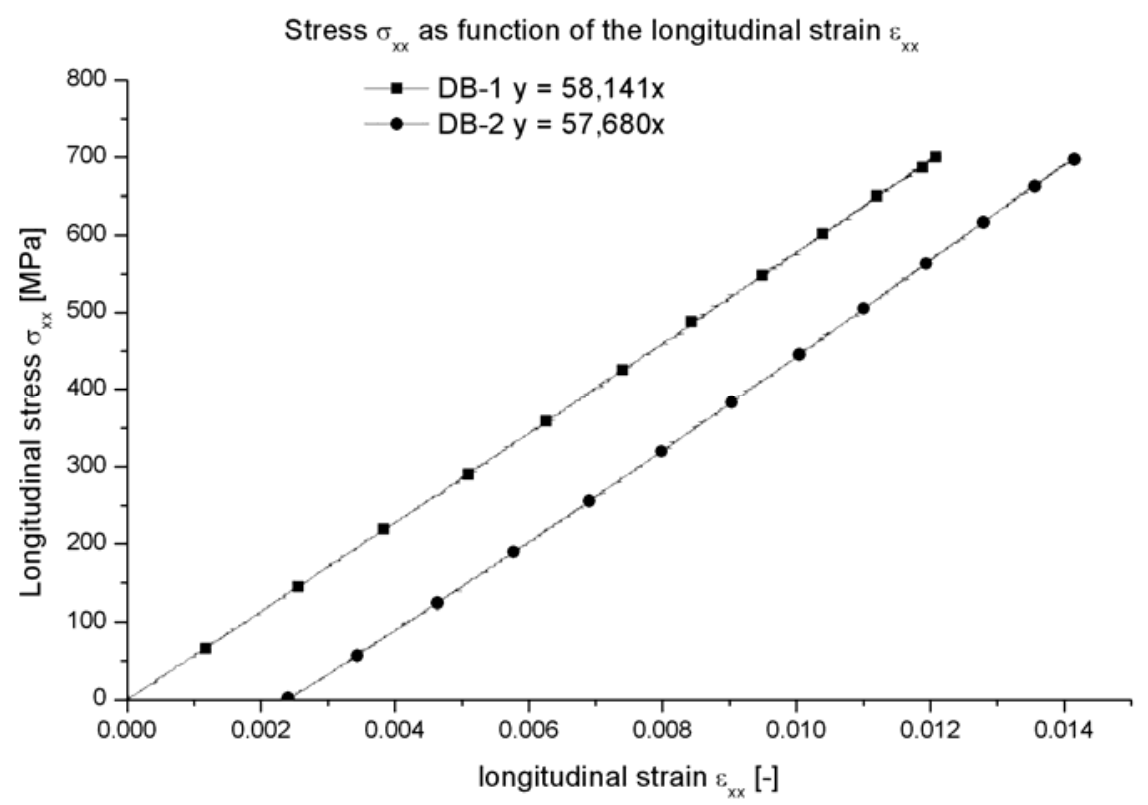

Figure 7 Longitudinal stress as function of the longitudinal strain for the geometry with $\mathrm{R}$ equal to $1446 \mathrm{~mm}$.

Not all experiments are shown here, but for all five conducted quasi-static experiments, an average failure stress of $768.8 \mathrm{MPa}$ was found, the maximum achieved stress was $828 \mathrm{MPa}$, but both values are significantly higher than the ones achieved with the rectangular shaped specimens.

Figure 8 illustrates some of the failed specimens. It should be noted that failure does not occur exactly in the centre of the specimen, but slightly above. This, however, is the location of the stress concentration for this geometry (see Figure 5 (a)) and was therefore predicted.

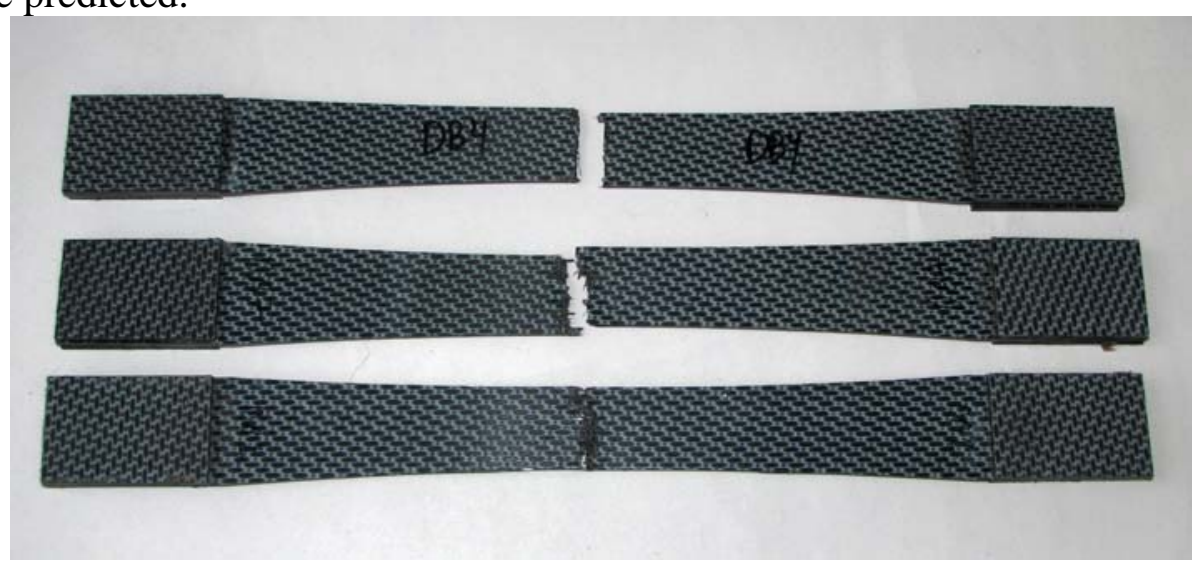

Figure 8 Illustration of static failures.

It can be remarked that the entire geometry is in fact based on the stress concentration factor of 1.3, which was previously derived using finite element modelling. It is of course possible that this factor may overestimate the real stress concentration. Therefore, two extra geometries, corresponding to two lower stress concentration factors, were also considered. For the first, the SCF of 1.2 was chosen, which yields $\mathrm{R}=2001 \mathrm{~mm}$ and for the second, an SCF of 1.1 was selected, yielding $\mathrm{R}=3667 \mathrm{~mm}$. Both geometries were tested, but both always failed in or underneath the end tabs; the 
corresponding failure stresses, however, where in the same order of magnitude than for the $\mathrm{R}=1446 \mathrm{~mm}$ geometry.

\subsection{Fatigue experiments}

Similar to the previous study [1], all fatigue tests here are done in load-controlled mode with a minimum stress of $0 \mathrm{MPa}$ and a certain maximum $\sigma_{\max }$. Furthermore, both $2 \mathrm{~Hz}$ and $5 \mathrm{~Hz}$ experiments are conducted. Since the quasi-static experiments already yielded promising results, a first fatigue test was conducted with $\sigma_{\max }=575 \mathrm{MPa}$ at $5 \mathrm{~Hz}$. This test survived over 3.6 million cycles and failed little above the centre of the specimen, which is a huge difference with the results from the previous fatigue study with rectangular specimens [1], where a maximum stress level of $575 \mathrm{MPa}$ almost always resulted in tab failure during run-in of the experiment. Other experiments with $\sigma_{\max }$ equal to 625, 650, 675 and $700 \mathrm{MPa}$ at both $2 \mathrm{~Hz}$ and $5 \mathrm{~Hz}$ were conducted. All of the specimens with $\mathrm{R}=1446 \mathrm{~mm}$ failed just above the centre of the specimen, again as predicted in the finite element simulations.

During the fatigue life, all specimens showed a similar behaviour. Figure 9 shows the evolution of the maximum, minimum and average value of the longitudinal strain during a $625 \mathrm{MPa} @ 2 \mathrm{~Hz}$ fatigue test. As can be seen, there is only limited permanent deformation, of which most occurs earlier in fatigue life. The difference between minimum and maximum strain level does not change significantly and given the fact that it is a load controlled test, this means that almost no stiffness degradation occurs. Around 1.8 million cycles, the rubber bands, holding the extensometer to the specimen, ruptured, so no strain data after this event is present. However, when observing the displacement during this test, a similar trend till failure at around 6 million cycles is present. Also, no significant rise in temperature was noted, similar to the results in [1].

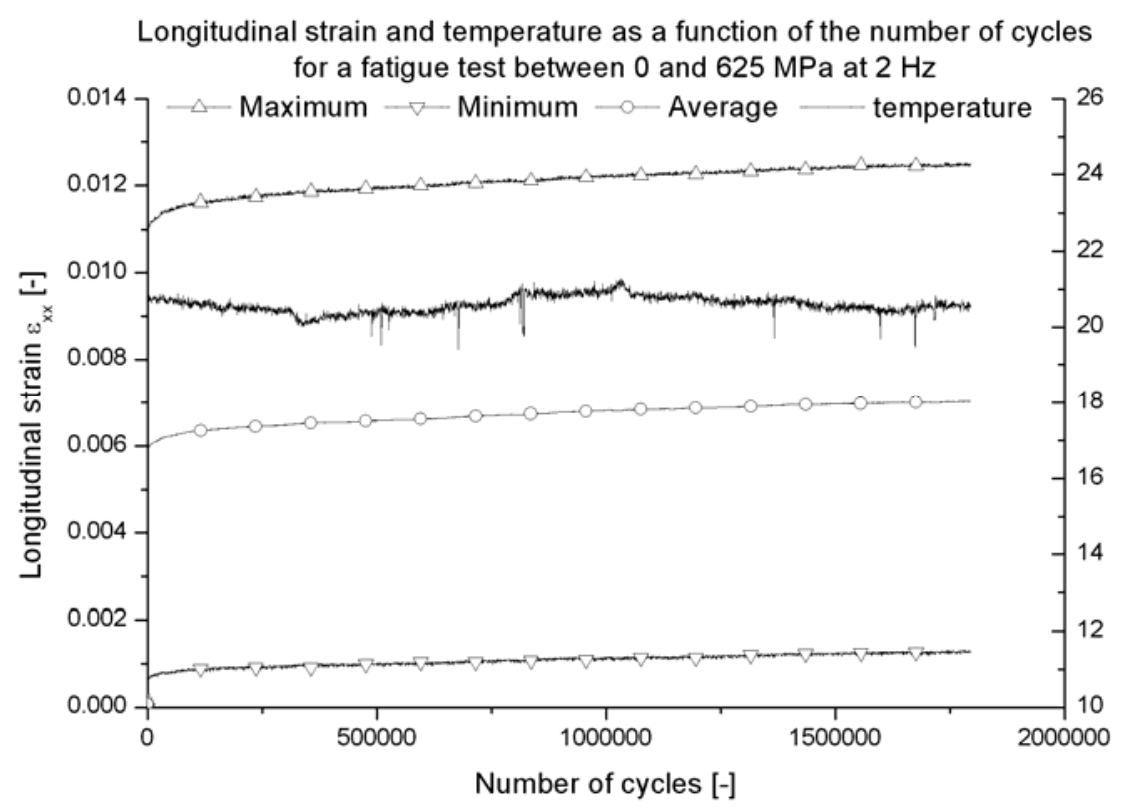

Figure 9 Maximum, minimum and mean value of the strain and the temperature during a 625 $\mathrm{MPa} @ 2 \mathrm{~Hz}$ fatigue experiment.

Similar to the static tests, also the geometries corresponding to the stress concentration factor of 1.2 and 1.1 were also tested under fatigue loading conditions. On both types, a $625 \mathrm{MPa} @ 2 \mathrm{~Hz}$ fatigue test was conducted, but both specimens failed in the tabbed section and compared to the dogbone with the $1446 \mathrm{~mm}$ radius, fatigue life is underestimated. Nevertheless, one could make the remark that both these geometries 
yield significantly higher fatigue life than with the rectangular specimens, where $625 \mathrm{MPa}$ could not even be reached under fatigue loading conditions [1].

A remark with respect to visible damage can be made. Although the samples were not polished, delaminations were clearly visible near the end of life. This was not the case for the rectangular specimens, but of course, they did not survive that many cycles. Also, the typical pull-out of the dogbone, as illustrated in Figure 10, was present near the end of the test. However, this does not influence the fatigue life, since failure always occurred near the centre of the specimen, so there was no interference between the longitudinal 'pull-out' cracks and the final, transverse failure.

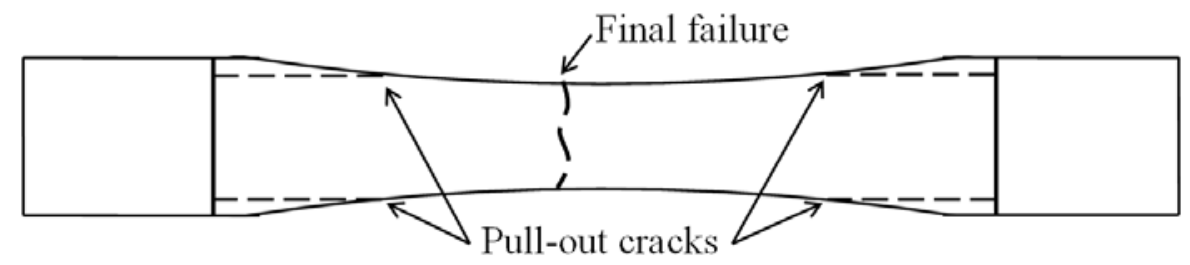

Figure 10 Illustration of the pull-out damage

To summarise, Figure 11 gives an overview of the maximum stress level and corresponding fatigue life. The experiments for the different stress concentration factors are also depicted (2Hz-radius DB). Apparently, there is only little influence of the frequency on the fatigue life for higher stress levels, whereas for stress levels lower than $675 \mathrm{MPa}$, a lower frequency yields a larger number of cycles to failure. For comparison purposes, the experiments with the rectangular shape specimens with the longest fatigue life are also added, but it is quite clear that the dogbone shape is superior. It should be noted that for the stress levels between 575 and $740 \mathrm{MPa}$, all rectangular specimens failed during run in, so no data as available.

Of course, further testing is necessary in order to study the fatigue behaviour in more detail, so that this frequency effect can be studied more thoroughly, the scatter on the results is known and that material models may be developed. The purpose of the experiments in this manuscript was to prove that the dogbone specimen indeed is a better geometry for this material for fatigue experiments.

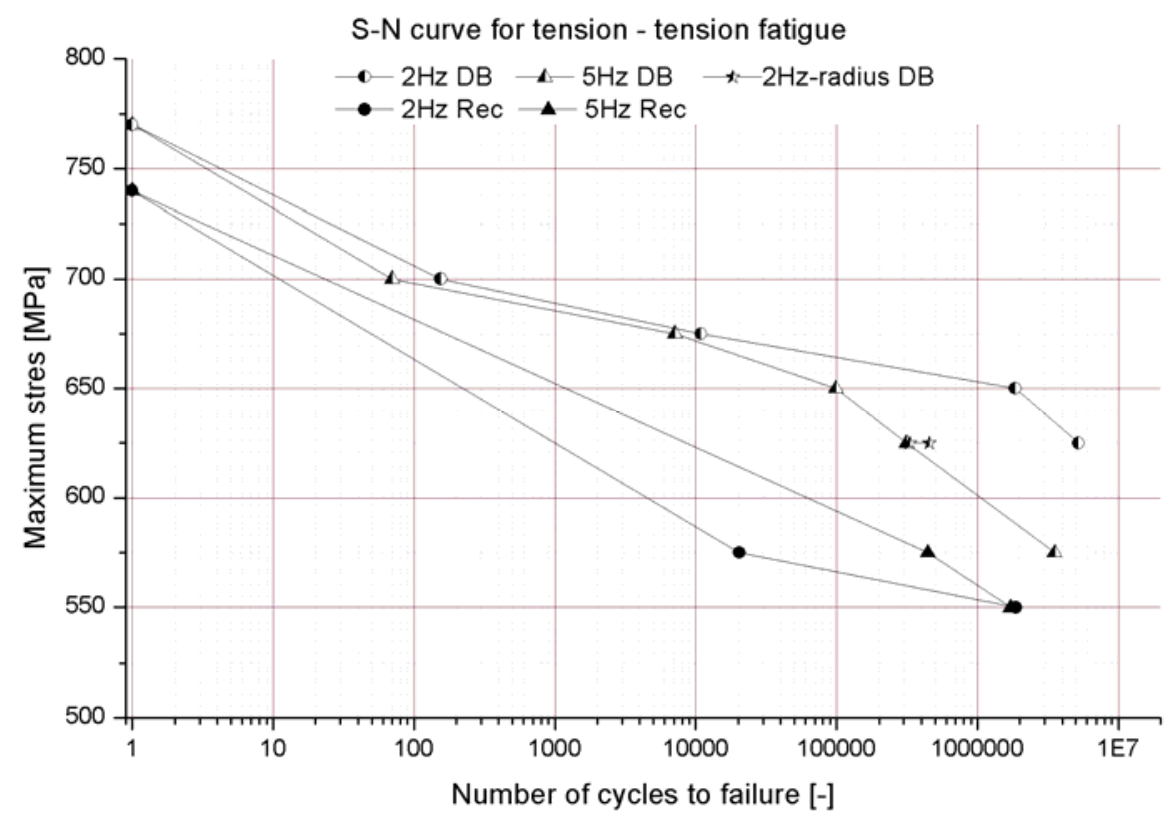

Figure 11 Maximum cycling stress as function of the fatigue life for $2 \mathrm{~Hz}$ and $5 \mathrm{~Hz}$ experiments. 


\section{Conclusions}

In this manuscript, a dogbone specimen was proposed for tension-tension fatigue experiments on a carbon fabric reinforced polyphenylene sulphide. First, the geometry was assessed using finite element modelling, where a stress concentration of 1.3 , caused by the end tabs, was taken into account. Based on these results, a dogbone shape with a length of $300 \mathrm{~mm}$ and a width of $30 \mathrm{~mm}$ was chosen. Using $50 \mathrm{~mm}$ for the end tabs, this left $200 \mathrm{~mm}$ of curved section and a radius of $1446 \mathrm{~mm}$. The strain distribution was also assessed, but the influence of the curvature on the strain distribution in the centre was negligible, meaning that extensometer or even strain gauge measurements will not be influenced.

With this geometry, both quasi-static and tension-tension fatigue experiments were conducted. Compared to the rectangular specimens, the quasi-static tests yielded higher failures stresses. Under fatigue loading conditions, it appears that with the rectangular shape, fatigue life is highly underestimated and with the dogbone, higher maximum load levels were possible. Furthermore, the specimen always failed just above the centre of the sample, as predicted by the simulations.

With respect to the fatigue behaviour, very little permanent deformation manifests itself and it mainly occurs early in fatigue life; very little stiffness degradation is present. Furthermore, there is only little influence of the frequency on the fatigue life for higher stress levels, whereas for stress levels lower than $675 \mathrm{MPa}$, a lower frequency yields a larger number of cycles to failure. Of course, further testing is necessary in order to study the fatigue behaviour in more detail, so that this frequency effect can be studied more thoroughly.

\section{Acknowledgements}

The authors are highly indebted to the Fund of Scientific Research - Flanders (F.W.O.) for sponsoring this research and to Ten Cate Advanced Composites for supplying the material.

\section{References}

[1] De Baere I., Van Paepegem W. Quaresimin M. and Degrieck J. On the tension-tension fatigue behaviour of a carbon reinforced thermoplastic part I: limitations of the ASTM D3039/D3479 standard. Polymer Testing, Volume 30, Issue 6, September 2011, Pages 625-632

[2] De Baere I., Van Paepegem W. and Degrieck J.. On the design of end tabs for quasi-static and fatigue testing of fibre-reinforced composites. Polymer Composites Volume 30, Issue 4, Pages 381-390, April 2009. http://dx.doi.org/10.1002/pc.20564

[3] Kulakov VL, Tarnopol'skii YM, Arnautov AK, Rytter J, Stress-strain state in the zone of load transfer in a composite specimen under uniaxial tension. MECHANICS OF COMPOSITE MATERIALS 40 (2): 91-100 MAR-APR 2004.

[4] Portnov, G. G., Kulakov, V. L., Arnautov, A. K., A refined stress-strain analysis in the load transfer zone of flat specimens of high-strength unidirectional composites in uniaxial tension 1. Theoretical analysis. MECHANICS OF COMPOSITE MATERIALS 42 (6): 547-554 NOVDEC 2006.

[5] Portnov, G. G., Kulakov, V. L., Arnautov, A. K., A refined stress-strain analysis in the load transfer zone of flat specimens of high-strength unidirectional composites in uniaxial tension 2. Finite-element parametric analysis. MECHANICS OF COMPOSITE MATERIALS 43 (1): 29-40 JAN-FEB 2007.

[6] Holmes, G. A., Wesson, Sheldon, McDonough, W. G., Kim, J. H., Netravali, A., Walker, J. N. and Johnson R.A. , An automated testing machine for monitoring the evolution of fiber breaks. Journal of Materials Science 44 (8) pp 2007-2015 (2009)

[7] Moon CK, Mcdonough WG, Two fiber technique for a fragmentation test. POLYMER-KOREA 
19 (6) Pages: 835-845 (1995)

[8] Moon CK, Moon SH, Se CS, Cho HH, Study on the durability of carbon fiber/epoxy composite by two fiber fragmentation test. Polymer Korea 20 (1) pp116-125 (1996)

[9] Hou TH, Belvin HL, Johnston NJ, Automated tow placed LARC(TM)-PETI-5 composites. High Performance Polymers 13 (4)pp 323-336 (2001).

[10] Lee J , Soutis C and Kong C, Static compressive strength of unidirectional carbon fibre-epoxy laminate. Advances in Composite Materials and Structures, Pts 1 and 2. Key Engineering Materials volume 334-335 pp 357-360 (2007)

[11] Curtis PT, Gates J, Molyneux CG, An improved engineering test method for measurement of the compressive strenght of unidiretional carbon fiber composites. Composites 22 (5) pp 363368 (1991)

[12] Kumagai S, Shindo Y, Horiguchi K, Takeda T, Mechanical characterization of CFRP woven laminates between room temperature and $4 \mathrm{~K}$. JSME International Journal series A: Solid Mechanics and Material Engineering 46 (3) pp 359-364 (2003)

[13] Aceves, C. M., Skordos, A. A. and Sutcliffe, M. P. F., Design selection methodology for composite structures. Materials \& Design 29 (2) pp 418-426 (2008)

[14] Andrew L. Gyekenyesi, Isothermal Fatigue, Damage Accumulation, and Life Prediction of a Woven PMC. NASA/CR - 1998-206593, Cleveland State University, Cleveland, Ohio (1998)

[15] J.A.M. Ferreira, J.D.M. Costa , P.N.B. Reis , M.O.W. Richardson, Analysis of fatigue and damage in glass- ${ }^{\circledR} b r e-$ reinforced polypropylene composite materials. Composites Science and Technology 59 (1999) pp 1461-1467

[16] Hochard C. Optimum design of laminated composite structures. Composite Structures 63 (2) Pages: 159-165 (2004)

[17] Payan J. and Hochard C., Damage modelling of carbon/epoxy laminated composites under static and fatigue loads. International Journal of Fatigue, 24, pp 299-306, (2002)

[18] De Baere I., Van Paepegem W., Degrieck J., Sol H., Van Hemelrijck D. and Petreli A., Comparison of different identification techniques for measurement of quasi-zero Poisson's ratio of fabric reinforced laminates. Composites A 38 (9) pp. 2047-2054. (2007)

[19] Daggumati S, Van Paepegem W. Degrieck J. Xu J. Lomov SV and Verpoest I., Local Damage in 5-harness satin weave composite under static tension: part II: meso-FE modelling.. ACCEPTED for Composite Science and Technology http://dx.doi.org/10.1016/j.compscitech.2010.07.002 